\title{
Papers
}

\section{Sensitisation to airborne moulds and severity of asthma: cross sectional study from European Community respiratory health survey}

\author{
Mahmoud Zureik, Catherine Neukirch, Bénédicte Leynaert, Renata Liard, Jean Bousquet, \\ Françoise Neukirch, on behalf of the European Community Respiratory Health Survey
}

\begin{abstract}
Objective To assess whether the severity of asthma is associated with sensitisation to airborne moulds rather than to other seasonal or perennial allergens. Design Multicentre epidemiological survey in 30 centres.

Setting European Community respiratory health survey.

Participants 1132 adults aged 20-44 years with current asthma and with skin prick test results. Main outcome measure Severity of asthma according to score based on forced expiratory volume in one second, number of asthma attacks, hospital admissions for breathing problems, and use of corticosteroids in past 12 months.

Results The frequency of sensitisation to moulds (Alternaria alternata or Cladosporium herbarum, or both) increased significantly with increasing asthma severity (odds ratio 2.34 (95\% confidence interval 1.56 to 3.52 ) for either for severe $v$ mild asthma). This association existed in all of the study areas (gathered into regions), although there were differences in the frequency of sensitisation. There was no association between asthma severity and sensitisation to pollens or cats. Sensitisation to Dermatophagoides pteronyssinus was also positively associated with severity. In multivariable logistic regressions including sensitisation to moulds, pollens, $D$ pteronyssinus, and cats simultaneously, the odds ratios for sensitisation to moulds were 1.48 ( 0.97 to 2.26 ) for moderate $v$ mild asthma and 2.16 (1.37 to 3.35) for severe $v$ mild asthma ( $\mathrm{P}<0.001$ for trend).

Conclusions Sensitisation to moulds is a powerful risk factor for severe asthma in adults. This should be taken into account in primary prevention, management, and patients' education.
\end{abstract}

\section{Introduction}

The severity of asthma varies widely between patients. Mild cases are characterised by normal lung function and patients are asymptomatic most of the time, whereas severe cases are characterised by permanently impaired lung function and frequent exacerbations. Little is known about the factors associated with sever- ity, but the identification of such factors is necessary for management and prevention.

Sensitisation to airborne allergens might be involved in the underlying mechanisms of severity. The associations between exposure, sensitisation, and asthma have suggested that house dust mite, ${ }^{12}$ animal dander, ${ }^{3}{ }^{4}$ cockroaches, ${ }^{5}$ pollens, ${ }^{6}$ and mould spores ${ }^{7}$ have a causal role in development. However, the associations between sensitisation to different allergens and the severity of asthma have been poorly explored.

Sensitisation to moulds has been suggested as a risk factor for life threatening asthma. In a study of 11 patients with episodes of respiratory arrest, 10 had positive results on skin prick testing for Alternaria alternata compared with only 31 of the 99 matched controls with asthma and no history of respiratory arrest. ${ }^{8}$ It was recently reported that 20 of 37 (54\%) patients admitted to an intensive care unit for asthma had a positive result on skin testing for one or more fungal allergens (Alternaria tenuis, Cladosporium cladosporoides, Helminthosporium maydis, or Epicoccum nigrum) compared with $30 \%$ in patients not admitted to intensive care units. The patients admitted to intensive care units were no more likely than the other patients to have positive results on skin tests for grasses, cat dander, or house dust mites. ${ }^{9}$ Furthermore, a study of the effects of environmental moulds during the pollen season showed that mean concentrations of mould spores, but not of tree, grass, or ragweed pollen, were significantly higher on the days when there were deaths related to asthma than on the days when no such deaths occurred. ${ }^{10}$ Thus there is evidence for an association between sensitisation and exposure to moulds and life threatening exacerbations of asthma However, the hypothesis that sensitisation to moulds is generally associated with the severity of asthma remains to be investigated.

In a preliminary study based on data from population samples of young adults collected in two French centres we found that sensitisation to Alternaria was associated with severity of asthma in a population of young adults. However, few participants had severe asthma $(n=21)$ and there were not enough positive results on skin prick tests to investigate the effect of other moulds. ${ }^{11}$
National Institute of Health and Medical Research (INSERM), Unit 408 Epidémiologie, Faculté de Médecine Xavier Bichat, BP 416 75870 Paris CEDEX 18, France Mahmoud Zureik epidemiological researcher

Catherine Neukirch senior physician in allergology

Bénédicte Leynaert epidemiological researcher

Renata Liard epidemiologist Françoise Neukirch senior epidemiological researcher

National Institute of Health and Medical Research

(INSERM), Unit

U454 Hôpita

Arnaud de

Villeneuve, 34295

Montpellier Cedex

05 , France

Jean Bousquet professor

Correspondence to: Mahmoud Zureik

zureik@vjf.inserm.fr

bmj.com 2002;325:411 
We used data from 1132 people with asthma from the entire dataset of the European Community respiratory health survey to assess whether the severity of asthma is associated with sensitisation to airborne moulds rather than to other seasonal or perennial allergens.

\section{Methods}

The methods of the survey have been fully described elsewhere. ${ }^{12}{ }^{13}$ Briefly, participating centres randomly selected samples of 20 to 44 year olds. Participants completed a short postal questionnaire about asthma and asthma-like symptoms (stage 1). At stage 2 about $20 \%$ random subsamples of responders were invited to attend a local test centre to complete a more detailed questionnaire administered by an interviewer and undergo skin prick and blood tests, assessment of lung function by spirometry, and airway challenge with methacholine. In addition, all participants who were not in the random subsamples but who reported in the postal questionnaire that they had been woken up by an attack of shortness of breath, had had at least one asthma attack in the past 12 months, or were currently taking medicine for asthma were also invited to participate in the stage 2 (symptomatic sample). The detailed questionnaire included questions about smoking, occupation, social status, home environment, medication, and use of services. ${ }^{13}$

Standardised skin prick tests were carried out with allergen coated lancets (Phazets, Pharmacia Diagnostics, Uppsala, Sweden). The allergens selected in all centres were A alternata, Cladosporium herbarum, Phleum pratense (timothy grass), birch, olive, Parietaria judaica (pellitory-of-the-wall), common ragweed (Ambrosia artemisifolia), Dermatophagoides pteronyssinus (house dust mite), and cat. An uncoated lancet was used as the negative control. Tests were performed on the volar surface of the forearm with a standard template. Weal size was recorded at 15 minutes as the biggest diameter and the diameter at $90^{\circ}$ to its midpoint, each to the nearest whole millimetre. The mean weal diameter was calculated as the average of the two diameters. Results were regarded as positive if the mean weal diameter was at least $3 \mathrm{~mm}$ greater than that for the negative control. Baseline forced expiratory volume in one second and forced vital capacity were measured by standardised methods, most often with a Biomedin spirometer (Biomedin, Padua, Italy). ${ }^{14}$

\section{Definitions of asthma and severity}

Participants were defined as currently having asthma if they answered yes to the question"Have you ever had asthma?"and if they had had at least one asthma attack or had taken inhaled or oral corticosteroids for asthma in the past 12 months. Asthma was classified as mild, moderate, or severe according to a score derived from Ronchetti et $\mathrm{al}^{15}$ and based on the forced expiratory volume in one second (mild $>80 \%$, moderate $70-80 \%$, severe $<70 \%$ predicted), the number of asthma attacks in the past 12 months $(2,3-6,>6)$, the number of admissions to hospital for breathing problems in the past 12 months $(0,1-2,>2)$, and whether inhaled or oral corticosteroids had been taken in the past 12 month. Each of the first three variables had three levels of increasing severity (scored 1, 2, 3) and the fourth variable had two levels (scored 1 or 2). The overall total score therefore ranged from 4 to 11 , with levels of severity levels being mild (score 4 or 5), moderate (6), or severe $(\geqslant 7)$.

\section{Analysis}

We used the data from stage 2 from the 30 centres that performed skin prick tests for the nine allergens mentioned above. The population, response rate, and prevalence of asthma in the centres have been reported previously. ${ }^{16-18}$ Of the 17089 participants examined for stage 2 in those 30 centres, complete data for all skin prick tests were available for 14098 . Of those, 1351 currently had asthma and in 1132 severity could be classified (missing data: 35 for forced expiratory volume in one second, 181 for the number of attacks, and 3 for both). The 1132 participants included in the analysis did not differ according to age, sex, smoking, or result to skin prick test from the 219 patients who could not be classified. Figure 1 shows details of the study design and the numbers of participants involved at each stage.

We used the SAS-PC statistical package (SAS Institute, Cary, NC) for statistical analysis. We assessed the associations between severity of asthma (mild, moderate, severe) and categorical variables using $\chi^{2}$ test and tested for trend with Mantel-Haenszel tests. We gathered data from the 30 centres within regions: United Kingdom and Republic of Ireland), northern Europe (Iceland, Norway, Sweden), central Europe (Belgium, France, the Netherlands), southern Europe (Italy and Spain), Australia and New Zealand, and United States (Portland was the only area in the United States). As we found no heterogeneity between regions in the association between severity and sensitisation to allergens $(\mathrm{P}>0.30$ for all allergens except $D$ pteronyssinus, for which $\mathrm{P}=0.13$ ) we performed logistic regressions to estimate adjusted odds ratios for the associations between severity and sensitisation, taking potential confounding factors into account and with regions included in the model as an additional explanatory variable. We used nominal logistic regressions to assess odds ratios for moderate versus mild

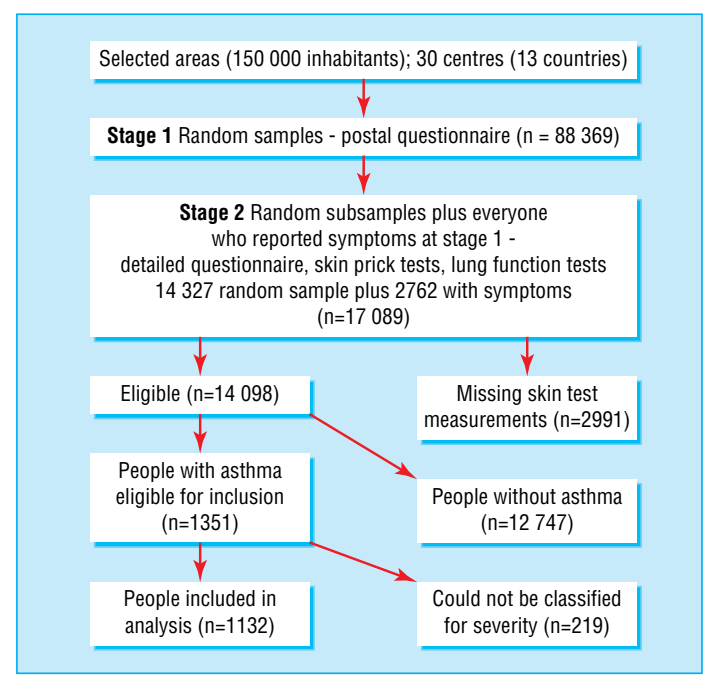

Fig 1 Study design and patients involved at each stage for 30 centres included in present analysis 
asthma and for severe versus mild asthma (without a linearity hypothesis). We used ordinal regression to test for linear trends of the associations between sensitisation and the three categories of severity.

\section{Results}

Of the 1132 people with asthma in this study, 564 $(50 \%)$ had mild asthma, 333 (29\%) had moderate asthma, and 235 (21\%) had severe asthma. Severity was not related to age, sex, smoking, passive smoking, or parental history of asthma (table 1). Table 1 also shows the features of severity that we used to classify participants into categories.

The proportion of people with mild asthma varied according to geographical area, ranging from $63 \%$ in southern Europe to $42 \%$ in Australia and New Zealand. The proportion with severe asthma was $15 \%$ in southern Europe, $17 \%$ in central Europe, $17 \%$ in northern Europe, 21\% in the United Kingdom and Republic of Ireland, 28\% in Australia and New Zealand, and 26\% in Portland.

Over $73 \%$ of participants were sensitised to at least one allergen and $65 \%$ were sensitised to two or more. Sensitisation to moulds alone was extremely rare: nine people were sensitised to Alternaria only and two to Cladosporium only. The proportion of people with asthma with sensitisation to the various allergens varied according to the regions (table 2). Sensitisation to moulds was the lowest in southern Europe and the highest in Portland and in the United Kingdom and Republic of Ireland.

Table 3 shows that sensitisation to moulds was significantly associated with severity of asthma. For both Alternaria and Cladosporium the proportion of sensitised people increased with increasing severity ( $\mathrm{P}<0.001$ for trend). For Alternaria the odds ratio was 1.64 for moderate versus mild asthma and 2.05 for severe versus mild asthma. These remained unchanged in the multivariable models after we adjusted for possible confounding factors. For Cladosporium the odds ratio was $>3$ for severe versus mild asthma. When we considered sensitisation to either mould, the odds ratio was 2.34 for severe versus mild asthma $(\mathrm{P}<0.001)$. We observed similar patterns for the association between sensitisation to moulds and severity of asthma (severe versus mild asthma) in all regions (fig 2).

We found no association between severity of asthma and sensitisation to pollens. Table 4 shows the
Table 1 Characteristics of study population. Figures are numbers (percentage) of participants unless stated otherwise

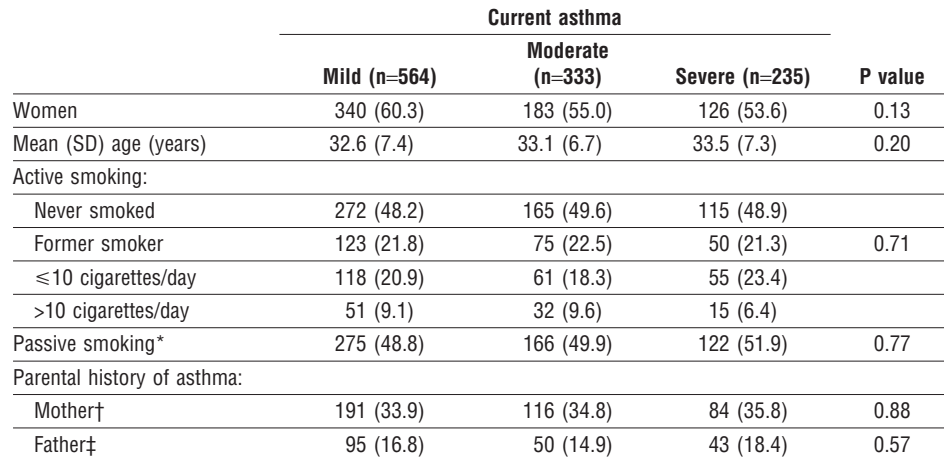

Features for severity of asthma

Forced expiratory volume in one second (\% predicted)

\begin{tabular}{|c|c|c|c|}
\hline$>80$ & $556(98.6)$ & $286(85.9)$ & $120(51.1)$ \\
\hline $70-80$ & $8(1.4)$ & $42(12.6)$ & $43(18.3)$ \\
\hline$<70$ & 0 & $5(1.5)$ & $272(30.6)$ \\
\hline \multicolumn{4}{|l|}{ Attacks§: } \\
\hline$\leqslant 2$ & $394(69.9)$ & $37(11.1)$ & $28(11.9)$ \\
\hline $3-6$ & $170(30.1)$ & $106(31.8)$ & $42(17.9)$ \\
\hline$>6$ & 0 & $190(57.1)$ & $165(70.2)$ \\
\hline \multicolumn{4}{|l|}{ Hospital admissions§: } \\
\hline None & $560(99.3)$ & $322(96.7)$ & $212(90.2)$ \\
\hline$\leqslant 2$ & $4(0.7)$ & $11(3.3)$ & $18(7.7)$ \\
\hline$>2$ & 0 & 0 & $5(2.1)$ \\
\hline Inhaled corticosteroids§ & $175(31.0)$ & $109(32.7)$ & $192(81.7)$ \\
\hline Oral corticosteroids§ & 31 (5.5) & $24(7.2)$ & $55(23.4)$ \\
\hline
\end{tabular}

Data missing for *6, $† 73, \ddagger 76$.

§ln past 12 months.

results for timothy grass and birch and sensitisation to at least one of the pollens tested. The latter results were identical when we excluded $P$ judaica and ragweed, which are not ubiquitous, from the definition of sensitisation to any pollen.

Severity of asthma was positively associated with sensitisation to $D$ pteronyssinus but not with sensitisation to cats (table 5). To assess the independent relations between the various allergens and severity of asthma we carried out simultaneous logistic regressions including sensitisation to moulds, pollens, $D$ pteronyssinus, and cats (table 6). For moulds (Alternaria or Cladosporium, or both) the odds ratios were 1.48 for moderate versus mild asthma and 2.16 for severe versus mild asthma.

Table 2 Proportions (\%) of participants with asthma with sensitisation to allergens tested in six regions of European Community respiratory health survey (ECRHS)

\begin{tabular}{|c|c|c|c|c|c|c|c|c|}
\hline Allergen & $\begin{array}{c}\text { All } \\
(n=1132)\end{array}$ & $\begin{array}{l}\text { UK and Republic of } \\
\text { Ireland }(n=205)\end{array}$ & $\begin{array}{c}\text { Northern } \\
\text { Europe } \\
(n=264)\end{array}$ & $\begin{array}{c}\text { Central } \\
\text { Europe } \\
(\mathrm{n}=139) \\
\end{array}$ & $\begin{array}{l}\text { Southern } \\
\text { Europe } \\
(n=150)\end{array}$ & $\begin{array}{c}\text { Australia/New } \\
\text { Zealand }(n=335)\end{array}$ & $\begin{array}{l}\text { Portland (US) } \\
(\mathrm{n}=39)\end{array}$ & $P$ value* \\
\hline Alternaria alternata & 11.9 & 17.6 & 10.2 & 13.7 & 4.7 & 10.5 & 28.2 & $<0.001$ \\
\hline Cladosporium herbarum & 5.8 & 6.8 & 9.9 & 4.3 & 0.7 & 4.5 & 10.3 & $<0.003$ \\
\hline Timothy grass & 41.3 & 44.4 & 39.4 & 38.1 & 34.0 & 44.8 & 48.7 & 0.18 \\
\hline Birch & 19.4 & 8.8 & 39.8 & 18.0 & 10.0 & 13.1 & 33.3 & $<0.001$ \\
\hline Olive & 7.2 & 1.0 & 6.1 & 15.1 & 18.0 & 4.2 & 5.1 & $<0.001$ \\
\hline Parietaria judaica & 3.5 & 1.5 & 1.9 & 5.0 & 12.0 & 1.7 & 2.6 & $<0.001$ \\
\hline Ragweed & 2.6 & 2.9 & 3.8 & 3.6 & 2.7 & 0.3 & 7.7 & 0.03 \\
\hline Dermatophagoides pteronyssinus & 47.7 & 58.1 & 23.5 & 48.2 & 34.0 & 67.2 & 41.0 & $<0.001$ \\
\hline Cat & 31.4 & 27.8 & 52.7 & 31.6 & 18.7 & 22.7 & 28.1 & $<0.001$ \\
\hline At least 1 allergen & 73.4 & 70.7 & 71.6 & 74.8 & 62.7 & 80.6 & 74.4 & $<0.002$ \\
\hline
\end{tabular}

${ }^{*} \mathrm{P}$ value for overall differences among regions. 
Table 3 Associations between sensitisation to moulds and severity of asthma (\% of sensitised participants by severity and odds ratios (95\% confidence interval) for moderate versus mild asthma and severe versus mild asthma)

\begin{tabular}{|c|c|c|c|c|}
\hline & \multicolumn{3}{|c|}{ Current asthma } & \multirow[b]{2}{*}{$P$ value for trend } \\
\hline & Mild $(n=564)$ & Moderate $(\mathrm{n}=\mathbf{3 3 3})$ & Severe $(n=235)$ & \\
\hline \multicolumn{5}{|l|}{ Alternaria alternata } \\
\hline$\%$ sensitised & 8.9 & 13.8 & 16.6 & $<0.001$ \\
\hline Unadjusted odds ratio & 1 & 1.64 (1.08 to 2.52$)$ & $2.05(1.31$ to 3.21$)$ & $<0.001$ \\
\hline Multivariate adjusted odds ratio* & 1 & 1.61 (1.04 to 2.50) & 2.03 (1.26 to 3.27$)$ & $<0.001$ \\
\hline \multicolumn{5}{|l|}{ Cladosporium herbarum } \\
\hline$\%$ sensitised & 3.9 & 5.4 & 11.1 & $<0.001$ \\
\hline Unadjusted odds ratio & 1 & 1.41 (0.74 to 2.66$)$ & 3.07 (1.70 to 5.50$)$ & $<0.001$ \\
\hline Multivariate adjusted odds ratio* & 1 & 1.21 (0.62 to 2.36) & 3.20 (1.72 to 5.94$)$ & $<0.001$ \\
\hline \multicolumn{5}{|l|}{ Either mould } \\
\hline$\%$ sensitised & 10.8 & 15.9 & 22.1 & $<0.001$ \\
\hline Unadjusted odds ratio & 1 & 1.56 (1.05 to 2.32) & 2.34 (1.56 to 3.52 ) & $<0.001$ \\
\hline Multivariate adjusted odds ratio* & 1 & $1.48(0.98$ to 2.24$)$ & 2.34 (1.52 to 3.60$)$ & $<0.001$ \\
\hline
\end{tabular}

${ }^{*}$ Adjusted for age, sex, smoking, passive smoking, parental history of asthma, and region.

Table 4 Associations between sensitisation to pollens and severity of asthma (\% of sensitised participants by severity and odds ratios ( $95 \%$ confidence interval) for moderate versus mild asthma and severe versus mild asthma)

\begin{tabular}{|c|c|c|c|c|}
\hline \multirow[b]{2}{*}{ Allergen } & \multicolumn{3}{|c|}{ Current asthma } & \multirow[b]{2}{*}{$P$ value for trend } \\
\hline & Mild $(n=564)$ & Moderate $(\mathrm{n}=333)$ & Severe $(\mathrm{n}=\mathbf{2 3 5})$ & \\
\hline \multicolumn{5}{|l|}{ Timothy grass } \\
\hline$\%$ sensitised & 40.3 & 39.6 & 46.4 & 0.22 \\
\hline Unadjusted odds ratio & 1 & 0.98 (0.74 to 1.29$)$ & $1.28(0.95$ to 1.75$)$ & 0.22 \\
\hline Multivariate adjusted odds ratio* & 1 & $0.97(0.72$ to 1.73$)$ & $1.22(0.89$ to 1.70$)$ & 0.31 \\
\hline \multicolumn{5}{|l|}{ Birch } \\
\hline$\%$ sensitised & 19.0 & 20.4 & 19.2 & 0.81 \\
\hline Unadjusted odds ratio & 1 & 1.10 (0.78 to 1.54$)$ & 1.01 (0.69 to 1.49$)$ & 0.81 \\
\hline Multivariate adjusted odds ratio* & 1 & 1.07 (0.74 to 1.54$)$ & 1.09 (0.72 to 1.65$)$ & 0.56 \\
\hline \multicolumn{5}{|c|}{ Any pollen (timothy grass, birch, olive, Parietaria judaica, or common ragweed) } \\
\hline$\%$ sensitised & 47.0 & 48.7 & 52.8 & 0.17 \\
\hline Unadjusted odds ratio & 1 & 1.07 (0.82 to 1.40$)$ & $1.26(0.93$ to 1.71$)$ & 0.17 \\
\hline Multivariate adjusted odds ratio* & 1 & 1.08 (0.81 to 1.43$)$ & $1.26(0.91$ to 1.76$)$ & 0.14 \\
\hline
\end{tabular}

${ }^{*}$ Adjusted for age, sex, smoking, passive smoking, parental history of asthma, and region.

The results were virtually identical when we included the number of allergens the participants were sensitised to in the models.

\section{Discussion}

Our study of asthma from large population based samples of adults living in different countries showed that the severity of asthma is associated with sensitisation to Alternaria and Cladosporium but not to pollens.

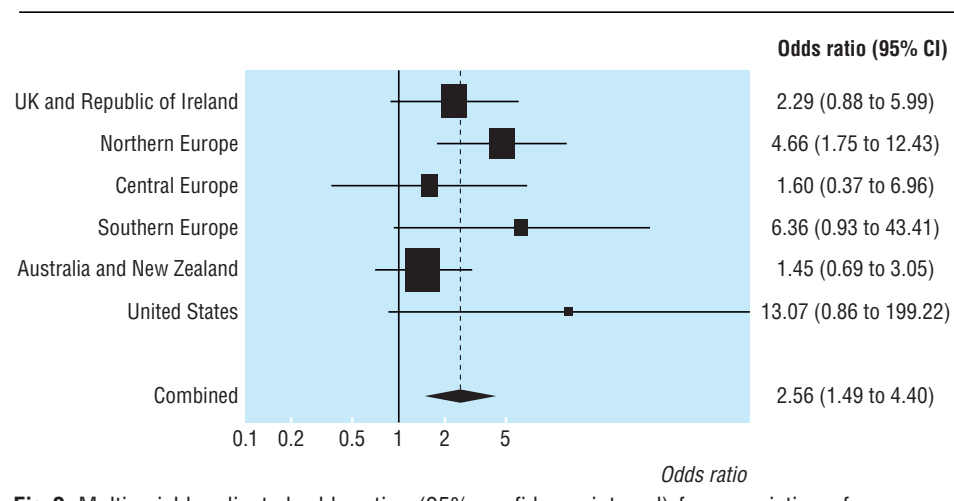

Fig 2 Multivariable adjusted odds ratios (95\% confidence interval) for association of severe versus mild asthma with sensitisation to moulds (either Alternaria alternata or Cladosporium herbarum, or both) by region (adjusted within region for age, sex, smoking habits, passive smoking, and parental history of asthma) with combined odds ratio from model with region included as random effect
As expected the severity of asthma was also associated with sensitisation to $D$ pteronyssinus.

\section{Comparison with other studies}

Previous studies have shown that sensitisation or exposure to moulds is associated with death from asthma, life threatening exacerbations, ${ }^{8-10}$ visits to emergency departments, ${ }^{19}$ and admissions to hospital for asthma, ${ }^{20}$ but this is the first population based study that used criteria other than healthcare attendance alone to show that sensitisation to moulds is a risk factor for severe asthma in adults.

The definition of severity of asthma in a population study is a difficult issue. ${ }^{21}$ We based our classification on a score that included some features considered as the most relevant. ${ }^{22}$ It is necessary to consider the use of drugs to control asthma in the classification of currently treated patients because otherwise participants would be classified according to control of asthma rather than severity. ${ }^{23}$ The inclusion of the use of corticosteroids in our definition may have influenced the distribution of severity in different areas because of variation in prescription from country to country. ${ }^{16}{ }^{17}$ Such variations do not allow international comparisons for the prevalence of severe asthma. However, similar patterns of results for the association between severity and sensitisation to moulds were observed in the different areas. Because it has been suggested that long term use of oral corticosteroids may modify results of skin prick tests ${ }^{24}$ we reanalysed 
Table 5 Associations between sensitisation to Dermatophagoides pteronyssinus or to cats and severity of asthma (\% of sensitised participants according to severity and odds ratios ( $95 \%$ confidence interval) for moderate versus mild asthma and severe versus mild asthma)

\begin{tabular}{|c|c|c|c|c|}
\hline \multirow[b]{2}{*}{ Allergen } & \multicolumn{3}{|c|}{ Current asthma } & \multirow[b]{2}{*}{$P$ value for trend } \\
\hline & Mild $(\mathrm{n}=564)$ & Moderate $(n=333)$ & Severe $(n=235)$ & \\
\hline \multicolumn{5}{|l|}{ Dermatophagoides pteronyssinus } \\
\hline$\%$ sensitised & 43.1 & 48.1 & 58.3 & $<0.001$ \\
\hline Unadjusted odds ratio & 1 & $1.22(0.93$ to 1.60$)$ & 1.85 (1.36 to 2.51$)$ & $<0.001$ \\
\hline Multivariate adjusted odds ratio* & 1 & $1.14(0.85$ to 1.53$)$ & 1.61 (1.14 to 2.26$)$ & $<0.002$ \\
\hline \multicolumn{5}{|l|}{ Cats } \\
\hline$\%$ sensitised & 30.9 & 29.4 & 35.3 & 0.32 \\
\hline Unadjusted odds ratio & 1 & $0.94(0.70$ to 1.26$)$ & 1.22 (0.89 to 1.69$)$ & 0.32 \\
\hline Multivariate adjusted odds ratio* & 1 & $0.92(0.67$ to 1.27$)$ & 1.37 (0.97 to 1.93$)$ & 0.21 \\
\hline
\end{tabular}

${ }^{\star}$ Adjusted for age, sex, smoking, passive smoking, parental history of asthma, and region.

Table 6 Associations between severity of asthma and sensitisation to moulds (Alternaria alternata or Cladosporium herbarum), pollens, Dermatophagoides pteronyssinus, and cats. Multivariate adjusted ${ }^{\star}$ odds ratio ( $95 \%$ confidence interval) for moderate versus mild asthma and for severe versus mild asthma

\begin{tabular}{|c|c|c|c|c|}
\hline \multirow[b]{2}{*}{ Allergen } & \multicolumn{3}{|c|}{ Current asthma } & \multirow[b]{2}{*}{$P$ value for trend } \\
\hline & Mild $(n=564)$ & Moderate $(n=333)$ & Severe $(n=235)$ & \\
\hline Moulds & 1 & 1.48 (0.97 to 2.26$)$ & 2.16 (1.37 to 3.35$)$ & $<0.001$ \\
\hline Pollens & 1 & $1.05(0.78$ to 1.42$)$ & $1.02(0.72$ to 1.45$)$ & 0.82 \\
\hline D pteronyssinus & 1 & 1.13 (0.83 to 1.54$)$ & 1.48 (1.04 to 2.11$)$ & $<0.05$ \\
\hline Cats & 1 & 0.85 (0.61 to 1.20$)$ & 1.07 (0.73 to 1.57$)$ & 0.62 \\
\hline
\end{tabular}

*Adjusted for age, sex, smoking, passive smoking, parental history of asthma, and region (all allergens included in models simultaneously).

the data after excluding the 110 patients taking oral corticosteroids. The multivariate adjusted odds ratios for the association between moulds (either Alternaria or Cladosporium) and severity were $1.65 \quad(95 \%$ confidence interval 1.08 to 2.50 ) for moderate versus mild asthma and 2.49 (1.55 to 3.99) for severe versus mild asthma. These results are similar to those presented in table 3 .

We considered hospital admissions in the past 12 months in the classification of asthma severity, but in only a few participants $(2.2 \%)$ was this relevant. Our results do not therefore duplicate those of previous studies of life threatening asthma.

To date, there has been little evidence that sensitisation to moulds is associated with severity of asthma. A study of 343 children aged 7 to 12 years recruited from a paediatric practice investigated the association between sensitisation to individual allergens and the frequency of episodes of wheezing. The proportion of children sensitised to A tenuis increased with the number of episodes. However, significant associations were also observed for sensitisation to mites and especially to cats. ${ }^{25}$ The relation between skin test reactivity and forced expiratory volume in one second was examined in children aged 6 to 12 years with asthma or frequent wheezing as part of the second national health and nutrition survey. Low forced expiratory volume in one second was associated with reactions to house dust, Alternaria, dogs, ragweed, oak, and Bermuda grass allergens. ${ }^{26}$

To our knowledge no population studies apart from the European Community respiratory health survey have investigated the association between severity of asthma and sensitisation to allergens in adults. In a study of the relative importance of sensitisation to individual allergens for bronchial hyperresponsiveness in the United Kingdom within the framework of the European survey, people with positive results to Cladosporium were considerably more responsive than those with positive results to cats or timothy grass. ${ }^{27}$ Analysis of Spanish data showed that sensitisation to Alternaria, cats, and timothy grass was associated with a decrease in forced expiratory volume in one second in women. ${ }^{28}$ In a preliminary study based on data from two French centres we found that sensitisation to Alternaria was associated with severity of asthma. ${ }^{11}$

As the importance of sensitisation to moulds as a risk factor for severe asthma may be dependent on area, the European survey was an unique opportunity to assess the consistency of the association. Data were collected with thoroughly standardised methods in comparable populations. Consistency of results across the survey areas has not always been observed for other issues. For example, the association between symptoms of asthma and lung function and the use of gas appliances varied considerably between areas. ${ }^{29} 30$ In contrast, the association between severity and sensitisation to moulds was remarkably consistent, though there were differences in the distribution of severity and in the frequency of sensitisation to the various allergens in the various areas, despite the fact the gathering of centres into regions is necessarily arbitrary.

We observed a differential association between moulds and pollens and severity of asthma. Possibly the size of fungal spores allows them to reach the lower airways and also they may be inhaled by means of fragments and other amorphous bioaerosols. Pollens are larger and their effect on asthma requires exceptional situations such as thunderstorms, when pollen is concentrated by changes in air flow, grains are ruptured by osmotic shock, and each grain releases hundreds of starch granules that are small enough to be respired. ${ }^{31}$ Other explanations for the different effects of sensitisation to moulds and to pollens are possible. Unlike pollens, moulds are present all through the year with increase in the spore counts during the autumn months. Also, the level of mould exposure is probably greater because the exposure occurs indoors rather than outdoors and people spend most 
What is already known on this topic

Sensitisation to moulds is a known risk factor for life threatening exacerbations of asthma

It is unknown whether such sensitisation is generally associated with severity of asthma

\section{What this study adds}

The prevalence of sensitisation to moulds (Alternaria alternata or Cladosporium herbarum, or both) increased with increasing severity of asthma

In this multicentre epidemiological survey, similar patterns of results were observed in various areas of the world

of their time indoors. The severity of asthma was associated with sensitisation to airborne moulds despite the fact that sensitisation to moulds alone was extremely rare. This might suggest a synergistic or additive effect of various sensitisations in determining severity. However, this is unlikely because when the number of positive test results was taken into account in the analysis the results did not change.

Our results of the associations between moulds and severity of asthma may be put together with results from studies on asthma incidence or outbreaks, where the role of moulds can be suspected for effects that were primarily attributed to other allergens. Moulds might be involved in the dramatic increase in incidence in Tucson that was initially attributed in part to a 10 -fold increase in atmospheric pollen due to the widespread use of ornamental trees that produce pollen. ${ }^{32}$ More recently, it has been suggested that moulds may have had a role in the asthma epidemics in Barcelona that were attributed to soybean. ${ }^{33}$

In conclusion, our results show that sensitisation to moulds might be involved in the severity of asthma. Given the increase of asthma and the prevalence of severe asthma in the past decades these results may be relevant for many people. Those people with asthma who are sensitised to airborne moulds should be educated to pay careful attention to symptoms and comply with treatment, particularly during the seasonal increase in mould spore counts. Patients should be encouraged to decrease exposure by avoiding indoor conditions that facilitate the growth of moulds-for example, by better ventilation and by decreasing dampness.

\section{Principal participants}

Coordinating centre (London): P Burney, S Chinn, C Luczynska, D Jarvis, E Lai.

Project management group: P Burney (project leader), S Chinn, C Luczynska, D Jarvis, P Vermeire (Antwerp), $\mathrm{H}$ Kesteloot (Leuven), J Bousquet (Montpellier), D Nowak (Hamburg), the late J Prichard (Dublin), R De Marco (Verona), B Rijcken (Groningen), J M Anto (Barcelona), J Alves (Oporto), G Boman (Uppsala), N Nielsen (Copenhagen), P Paoletti (Pisa).

Participating centres: Austria: W Popp (Vienna); Australia: M Abramson, J Kutin (Melbourne); Belgium: P Vermeire, F van Bastelaer (Antwerp South, Antwerp Central); France: J Bousquet, J Knani (Montpellier), F
Neukirch, R Liard (Paris), I Pin, C Pison (Grenoble), A Taytard (Bordeaux); Germany: H Magnussen, D Nowak (Hamburg), H E Wichmann, J Heinrich (Erfurt); Greece: N Papageorgiou, P Avarlis, M Gaga, C Marossis (Athens); Iceland: T Gislason, D Gislason (Reykjavik); Ireland: the late J Prichard, S Allwright, D MacLeod (Dublin); Italy: M Bugiani, C Bucca, C Romano (Turin), R de Marco Lo Cascio, C Campello (Verona), A Marinoni, I Cerveri, L Casali (Pavia); the Netherlands: B Rijcken, A Kremer, (Groningen, Bergen-op-Zoom, Geleen); New Zealand: J Crane, S Lewis, (Wellington, Christchurch, Hawkes Bay); Norway: A Gulsvik, E Omenaas (Bergen); Portugal: J A Marques, J Alves (Oporto); Spain:J M Antó, J Sunyer, F Burgos, J Castellsangué, J Roca, J B Soriano, A Tobías (Barcelona), N Muniozguren, J Ramos Gonzáles, A Capelastegui (Galdakao), J Castillo, J Rodriguez Portal (Seville), J Martinez-Moratalla, E Almar (Albacete), J Maldonado Pérez, A Pereira, J Sánchez (Huelva), J Quiros, I Huerta, F Pavo, (Oviedo); Sweden: G Boman, C Janson, E Björnsson (Uppsala), L Rosenhall, E Norrman, B Lundbäck (Umea), N Lindholm, P Plaschke (Gothenburg,); Switzerland: U AckermannLiebrich, N Künzli, A Perruchoud (Basle); United Kingdom: M Burr, J Layzell (Caerphilly), R Hall (Ipswich), B Harrison (Norwich), J Stark (Cambridge); United States: S Buist, W Vollmer, M Osborne (Portland).

Contributions: All authors conceived and initiated this study within the framework of the European Community respiratory health survey. MZ designed and performed the analysis, wrote the first draft of the paper, and is guarantor. CN helped with analysis, interpretation, and writing the paper. BL conducted part of the statistical analysis and helped in interpretation. RL gave substantial help to writing the paper. JB participated in study design and interpretation. FN was principal investigator and participated in study design, analysis, and interpretation. MZ and CN participated in the data collection for the Paris centre.

Funding: Australia: Allen \& Hanbury, Australia; Belgium: Belgian Science Policy Office, National Fund for Scientific Research; France: Ministère de la Santé, Glaxo France, Institut Pneumologique d'Aquitaine, Contrat de Plan Etat-Région Languedoc-Roussillon, CNMATS, CNMRT (90MR/10, 91AF/ 6), Ministre délégué de la santé, RNSP, Ministère de l'Environnement (No 96115-EN96D4); Germany: GSF, Bundesminister für Forschung und Technologie, Bonn; Greece: Greek Secretary General of Research and Technology, Fisons, Astra, Boehringer-Ingelheim; India: Bombay Hospital Trust; Italy: Ministero dell'Univesità e della Ricerca Scientifica e Tecnologica, CNR, Regione Veneto Grant RSF No 381/05.93; New Zealand: Asthma Foundation of New Zealand, Lotteries Grant Board, Health Research Council of New Zealand; Norway: Norwegian Research Council project No 101422/310; Portugal: Glaxo Farmacêutica Lda, Sandoz Portugesa; Spain: Ministero Sanidad y Consumo FIS (grants 91/0016060/OOE-05E, 92/0319, 93/0393), Hospital General de Albacete, Hospital General Juan Ramón Jiménenz, Consejeria de Sanidad Principado de Asturias; Sweden: Swedish Medical Research Council, Swedish Heart Lung Foundation, Swedish Association against Asthma and Allergy, Swedish Society of Medicine, Astra, Glaxo-Wellcome, Boehringer-Ingelheim; Switzerland: Swiss National Science Foundation Grant 4026-28099; United Kingdom: National Asthma Campaign, British Lung Foundation, Department of Health, South Thames Regional Health Authority; United States: US Department of Health, Education and Welfare Public Health Service Grant No 2 S07 RR05521-28.

Competing interests: None declared.

1 Sporik R, Holgate ST, Platts-Mills TAE, Cogswell JJ. Exposure to house-dust mite allergen (Der p I) and the development of asthma in childhood. A prospective study. N Engl J Med 1990;323:502-7. 
2 Peat JK, Tovey E, Toelle BG, Haby MM, Gray EJ, Mahmic A, et al. House dust mite allergens. A major risk factor for childhood asthma in Australia Am J Respir Crit Care Med 1996;153:141-6.

3 Ingram JM, Sporik R, Rose G, Honsinger R, Chapman MD, Platts-Mills TAE. Quantitative assessment of exposure to $\operatorname{dog}(\mathrm{Can} \mathrm{f} \mathrm{I})$ and cat (Fel d I) allergens: relation to sensitization and asthma among children living in Los Alamos, New Mexico. J Allergy Clin Immunol 1995;96:449-56.

4 Sporik R, Ingram JM, Price W, Sussman JH, Honsinger RW, Platts-Mills TAE. Association of asthma with serum IgE and skin test reactivity to allergens among children living at high altitude. Tickling the dragon's breath. Am J Respir Crit Care Med 1995;151:1388-92.

5 Rosenstreich DL, Eggleston P, Kattan M, Baker D, Slavin RG, Gergen P, et al. The role of cockroach allergy and exposure to cockroach allergen in causing morbidity among inner-city children with asthma. $N$ Engl J Med 1997:336:1356-63

6 Pollart SM, Reid MJ, Fling JA, Chapman MD, Platts-Mills TAE. Epidemiology of emergency room asthma in northern California: association with IgE antibody to ryegrass pollen. J Allergy Clin Immunol 1988;82:224 30 .

7 Halonen M, Stern DA, Wright AL, Taussig LM, Martinez FD. Alternaria as a major allergen for asthma in children raised in a desert environment. Am J Respir Crit Care Med 1997;155:1356-61.

8 O'Hollaren MT, Yunginger JW, Offord KP, Somers MJ, O'Connell EJ, Ballard DJ, et al. Exposure to an aeroallergen as a possible precipitating factor in respiratory arrest in young patients with asthma. $N$ Engl J Med 1991;324:359-63.

9 Black PN, Udy AA, Brodie SM. Sensitivity to fungal allergens is a risk factor for life-threatening asthma. Allergy 2000;55:501-4.

10 Targonski PV, Persky VW, Ramekrishnan V. Effect of environmental molds on risk of death from asthma during the pollen season. J Allerg Clin Immunol 1995;95:955-61.

11 Neukirch C, Henry C, Leynaert B, Liard R, Bousquet J, Neukirch F. Is sensitization to Alternaria alternata a risk factor for severe asthma? A population-based study. J Allergy Clin Immunol 1999;103:709-11.

12 Burney PGJ, Luczynska C, Chinn S, Jarvis D. The European Community respiratory health survey. Eur Respir J 1994;7:954-60.

13 European Commission, Directorate General XII. Protocol for the European Community respiratory health survey. Luxembourg: Office for Official Publications, 1993 (L-2920).

14 Roca J, Burgos F, Sunyer J, Saez M, Chinn S, Anto JM, et al. Reference values for forced spirometry. Eur Respir J 1998;11:1354-62.

15 Ronchetti R, Indinnimeo L, Bonci E, Corrias A, Evans D, HindiAlexander M, et al. Asthma self-management programmes in population of Italian children: a multicentric study. Eur Respir J 1997;10:1248-53.

16 Burney P, Chinn S, Jarvis D, Luczynska C, Lai E. Variations in the prevalence of respiratory symptoms, self-reported asthma attacks, and use of asthma medication in the European Community respiratory health survey (ECHRS). Eur Respir J 1996;9:687-95.

17 Janson C, Chinn S, Jarvis D, Burney P. Physician-diagnosed asthma and drug utilization in the European Community respiratory health survey. Eur Respir J 1997;10:1795-802.
18 Janson C, Anto J, Burney P, Chinn S, de Marco R, Heinrich J, et al, on behalf of the European Community Respiratory Health Survey II. The European Community respiratory health survey: what are the main results so far? Eur Respir J 2001;18:598-611.

19 Ross MA, Curtis L, Scheff PA, Hryhorczuk DO, Ramakrishnan V, Wadden RA, et al. Association of asthma symptoms and severity with indoor bioaerosols. Allergy 2000;55:705-11.

20 Hopkinson L, O'Driscoll BR. Mould allergy is common in patients with severe asthma requiring multiple hospital admissions [abstract]. Eur Respir J 1997;10 (suppl 25):28S.

21 Liard R, Leynaert B, Zureik M, Beguin FX, Neukirch F. Using global initiative for asthma guidelines to assess asthma severity in populations. Eur Respir J 2000;16:615-20.

22 National Heart Lung and Blood Institute. Global initiative for asthma. Global strategy for asthma management and prevention. NHLBI/WHO workshop report. Bethesda, MD: National Institutes of Health, 1995 (National Heart Lung and Blood Institute publication No 95-3659).

23 Cockcroft DW, Swystun VA. Asthma control versus asthma severity. J Allergy Clin Immunol 1996;98:1016-8.

24 Des Roches A, Paradis L, Bougeard YH, Godard P, Bousquet J, Chanez P. Long-term oral corticosteroid therapy does not alter the results of immediate-type allergy skin prick tests. J Allergy Clin Immuno 1996;98:522-7

25 Henderson FW, Henry MM, Ivins SS, Morris R, Neebe EC, Leu S-Y, et al. Correlates of recurrent wheezing in school-age children. Am J Respir Crit Care Med 1995; 151:1786-93.

26 Schwartz J, Weiss ST. Relationship of skin test reactivity to decrements in pulmonary function in children with asthma or frequent wheezing. $\mathrm{Am} J$ Respir Crit Care Med 1995;152:2176-80.

27 Chinn S, Jarvis D, Luczynska C, Burney P. Individual allergens as risk factors for bronchial responsiveness in young adults. Thorax 1998;53:662-7.

28 Sunyer J, Soriano J, Anto JM, Burgos F, Pereira A, Payo F, et al. Sensitization to individual allergens as risk factors for lower FEV1 in young adults. Int J Epidemiol 2000;29:125-30.

29 Jarvis D, Chinn S, Luczynska C, Burney P. Association of respiratory symptoms and lung function in young adults with use of domestic gas appliances. Lancet 1996;347:426-31.

30 Jarvis D, Chinn S, Sterne J, Luczynska C, Burney P. The association of respiratory symptoms and lung function with the use of gas for cooking. Eur Respir J 1998;11:651-8.

31 Newson R, Strachan K, Archibald E, Emberlin J, Hardaker P, Collier C. Effect of thunderstorms and airborne grass pollen on the incidence of acute asthma in England, 1990-94. Thorax 1997;52:680-5.

32 Sneller MR, Hayes HD, Pinnas JL. Frequency of airborne Alternaria spores in Tucson, Arizona over a 20 -year period. Ann Allergy 1981:46:30-3.

33 Codina R, Lockey RF. Possible role of molds as secondary etiologic agents of the asthma epidemics in Barcelona, Spain. J Allergy Clin Immunol 1998;102:318-20.

(Accepted 4 April 2002)

\section{Science commentary: Skin prick testing}

Skin prick testing is conventionally used to investigate immediate type hypersensitivity to allergens in patients with rhinoconjunctivitis, contact urticaria, asthma, atopic eczema, and suspected food allergy. It is also a means of detecting allergen specific $\operatorname{IgE}$ and has the advantage of being relatively inexpensive, providing immediate results compared with measurement of serum allergen specific IgE by radioallergosorbent testing (RAST).

The technique used for skin prick testing involves puncturing the skin with a calibrated lancet $(1 \mathrm{~mm})$ held vertically, or a hypodermic needle or blood lancet at an angle of $45^{\circ}$, and introducing a drop of diluted allergen. All patients undergoing skin prick testing should also have a positive histamine control and negative diluent (saline) control test included. An itchy weal should develop at the histamine puncture site within 10 minutes. Test solutions are standardised to give a mean weal diameter of $6 \mathrm{~mm}$. The maximum or mean diameter of the weals to various allergens should be read at 15 minutes. A weal of $3 \mathrm{~mm}$ or more in diameter is generally considered to represent a positive response (indicating sensitisation to the allergen). The negative control is important because it excludes the presence of dermographism, which if present makes the tests difficult to interpret.

The relevance of skin prick testing should be interpreted in the context of the patient's history. Positive results can occur in people without symptoms and, similarly, false negative results may occur. "Blanket" allergy testing (whether by skin prick testing or serological methods) can give false positive results and, particularly in the case of foods can lead to unnecessary dietary restrictions. Standardised solutions to a wide range of allergens are available commercially. For more labile allergens (such as those found in fruit and vegetables) fresh produce should be used. Skin prick tests to aeroallergens are generally considered safe, but intramuscular adrenaline should be available and full resuscitation facilities are needed when test are carried out with other allergens such as foods and natural rubber latex. 